\title{
ANALISIS KOMPARATIF HARGA TANDAN BUAH SEGAR DI KUD LIMBUR LUBUK MENGKUANG KABUPATEN BUNGO
}

\section{COMPARATIVE ANALYSIS OF FRESH FRUIT MARKET PRICES IN KUD WASTE BREATHING IN BUNGO DISTRICT}

\author{
Asminar \\ Program Studi Agribisnis, Fakultas Pertanian, Universitas Muara Bungo, Jl. Pendidikan, RT. 10 \\ RW. 02 No. 10 Kelurahan Sungai Binjai, Kecamatan Bathin III, Kabupaten Bungo, Jambi \\ 37228, Indonesia \\ asminarjabir@yahoo.com
}

\begin{abstract}
ABSTRAK
Penelitian ini untuk mengetahui Perkembangan harga tandan buah segar (TBS) Koperasi Unit Desa di Limbur Lubuk Mengkuang dan Kecamatan Bathin II PelayangKabupaten Bungo kompetitif harga tandan buah segar (TBS) Koperasi Unit Desa di dan Limbur Lubuk Mengkuang dan Kecamatan Bathin II Pelayang di Kabupaten Bungo. Penelitian ini di laksanakan dari tanggal 10Januari 2017 sampai tanggal 10 Februari 2017.Penelitian ini menggunakan data sekunder dengan rentang waktu (time series) dari Mulai 2010 sampai 2015 (dataper bulan) dan data pendukung yang dikumpulkan dari PT Jamika Raya, Koperasi Unit Desa di Bathin II Pelayang dan Koperasi Unit Desa di Kecamatan Limbur Lubuk Mengkuang, Dinas Perindustrian Dan Perdagangan Provinsi Jambi, Gapkindo,Badan Pusat Statistik Kabupaten Bungo,Badan Pusat Statistik Provinsi Jambi Dan Dinas Perkebunan Provinsi Jambi. Analisa data menggunkan Independen Sample T-Tes. Hasil penelitian menujukkan bahwa Perkembangan harga harga tandan buah segar (TBS) Koperasi Unit Desa di Limbur Lubuk Mengkuang dan Kecamatan Bathin II Pelayang Kabupaten Bungo dan tidak ada komparatif harga tandan buah segar (TBS) Koperasi Unit Desa di Limbur Lubuk Mengkuang dan Kecamatan Bathin II Pelayang Kabupaten Bungo
\end{abstract}

Kata Kunci: Harga ; Komparatif

\section{ABSTRACT}

This research was to find out the development of the price of fresh fruit bunches (TBS) of Village Unit Cooperatives in Limbur Lubuk Mengkuang and Bungin Pelayang District, Bungo Regency, competitive prices of fresh fruit bunches (TBS) in Lubuk Mengkuang and Limbur Village Unit Cooperatives and Bathin II Pelayang District in Bungo District. This research was carried out from 10 January 2017 to 0 Februari 2017. This study used secondary data with a time series from 2010 to 2015 (month dataper) and supporting data collected from PT Jamika Raya, Village Unit Cooperatives in Bathin II Village Unit Implementers and Cooperatives in Limbur Lubuk Mengkuang District, Jambi Province Office of Industry and Trade, Gapkindo, Bungo Regency Central Bureau of Statistics, Jambi Province Central Bureau of Statistics and Jambi Province Plantation Office. Data analysis uses Independent Sample T-Test. The results showed that the development of the price of fresh fruit bunches (TBS) of Village Unit 
Cooperatives in Limbur Lubuk Mengkuang and Bathin II Subdistrict of Bungo Regency and there was no comparative price of fresh fruit bunches (TBS) of Village Unit Cooperatives in Lubuk Mengkuang and Bathin II Pelayang Districts Bungo District

Keywords: Comparative; Price

\section{PENDAHULUAN}

\section{Latar Belakang}

Perkebunan kelapa sawit menjadi penyelamat perekonomian Indonesia ketika negara ini menghadapi krisis pada tahun 1998, hal ini di buktikan defisit perdagangan ekspor Indonesia dapat tertutupi dari surplus perdagangan non-migas yang kontributor utamanya produk kelapa sawit. Perkebunan sawit milik swasta, rakyat dan BUMN. sawit merupakan komoditas ekspor pertanian terbesar. Perkebunan kelapa sawit ini menjadi sarana meraih nafkah dan perkembangan ekonomi bagi sebagian besar masyarakat, menyediakan lebih dari 19,5 juta lapangan kerja bagi penduduk Indonesia (BPS, 2014)

Perkebunan sawit Indonesia diperkirakan akan terus berkembang pesat. Kebutuhan minyak sawit dunia mengalami pertumbuhan pesat dalam beberapa dasawarsa terakhir dengan produksi minyak sawit saat ini diperkirakan lebih dari 45 juta ton. Indonesia merupakan salah satu produsen dan eksportir minyak sawit terbesar di dunia, dengan produksi lebih dari 18 juta ton minyak sawit per tahun dan industri ini menopang sekitar 14\% PDB, Perkebunannya menyediakan lapangan kerja bagi lebih dari $41 \%$ penduduk Sektor pertanian dewasa ini sudah banyak diminati oleh masyarakat Indonesia, hampir disetiap daerah terdapat usaha sektor pertanian. Salah satu sektor pertanian adalah usaha perkebunan. Usaha perkebunan tidak hanya diusahakan oleh pengusaha besar dan pemerintah tetapi sudah juga diusahakan oleh masyarakat, umumnya walaupun dengan lahan yang terbataskerena usah di bidang perkebunan memiliki prospek yang cukup menjanjikan. Didominasi oleh perkebunan rakyat, perkebunan besar Negara dan perkebunanbesar swasta, pola kemitraan KKPA (Kredit Koperasi Pada Anggota).

Wulandari. dkk (2016) menyatakan bahwa pertumbuhan luas lahan selama sepuluh tahun terakhir mengalami 5,7\% dan pertumbuhan produksi sebesar $6 \%$ pertahun.Tanaman Kelapa Sawit adalah salah satu komiditi sektor pertanian dan subsektor perkebunan yang mempunyaiperan penting dalam pembangunan nasional. Komoditas dan subsektor perkebunan yang memilki luas areal lebih tinggi dibandingkan komoditas lainnya adalah kelapa sawit . Perkembangan perkebunan di Propinsi Jambi melalui ber bagai pola pengembangan kelapa sawit menunjukkan perkembangan yang baik sampai saat ini. Kabupaten di Provinsi jambi yang komoditi andalan utamanya kelapa sawit adalah Kabupaten Bungo. Mayoritas masyarakat di Kabupaten Bungo menanam kelapa sawit dengan luas lahan 114.060 ha tahun tahun 2015 (Dinas Perkebunan Provinsi Jambi, 2016)

Produksi kelapa sawit ini sangat erat hubungannya dengan harga yang di terima oleh petani. Petani di kabupaten Bungo mayoritas menjual kelapa sawitn ke PT karena harga Jualnya lebih tinggi. Hal ini sesuai dengan pendapat (Toar, dkk, 2017) yang menyatakan harga jual yang di tetapkan perusahaan lebih tinggi dari pada harga jual yang di tentukan berdasarkan metode cost plus pricing dan mark up pricing. Petani yang berada di kecamatan bathin II Pelayang dan Limbur Lubuk Mengkuang menjual Kelapa sawit ke menjual tandan buah segar ke Koperasi Unit Desa (KUD) kemudian Koperasi Unit Desa yang menjual TBS ke 
PT Jamika Raya . Petani yang menjual TBS ke KUD mayoritas adalah petani plasma, dan hanya sendikit petani non plasma, harga petani plasma lebih tinggi daripada petani non plasma, hal ini sesuai dengan pendapat (Widayana, 2016) yang menyatakan bahwa harga TBS petani plasma lebih tinggi dari harga TBS petani Plasma. KUD yang menjual TBS di PT Jamika Raya selengkapanya dapat di lihata pada tabel 1. di bawah ini:

Tabel I. Nama Koperasi yang terdapat di kecamatan bathin II pelayang dan Limbur Lubuk Mengkuang

\begin{tabular}{rlll}
\hline No & Nama KUD & Nama Dusun & Nama Kecamatan \\
\hline 1 & KUD SP II & Pulau Kerakap & Bathin II Pelayang \\
2 & KUD SP III & Tebo Jaya & Limbur Lubuk Mengkuang \\
3 & KUD SP IV & Tuo Limbur & Limbur Lubuk Mengkuang \\
4 & KUD SP V & Limbur Baru & Limbur Lubuk Mengkuang \\
5 & KUD SP VI & Sekar Mengkuang & Limbur Lubuk Mengkuang \\
\hline 6 & KUD SP VII & Seberang Jaya & Bathin II Pelayang \\
\hline
\end{tabular}

Sumber : PT Jamika Raya,2015

Tabel 1 menunjukkan bahwa di Limbur Lubuk Mengkuang menjual sawitnya Kecamatan Bathin II Pelayang terdapat dua ke PT Jamika Raya . Harga TBS kelapa sawit koperasi unit desa (KUD) terdapat di PT Jamika Raya dari tahun per tahun Kecamatan Limbur Lubuk Mengkuang . Enam mengalami fluktuasi, hal ini dapat dilihat pada koperasi unit desa (KUD) yang ada di Grafik 1.

kecamatan Bathin II Pelayang dan kecamatan

\section{Grafik.1.Harga Rata-R ata Tandan buah Segar PT Jamika Raya tahun 2015}

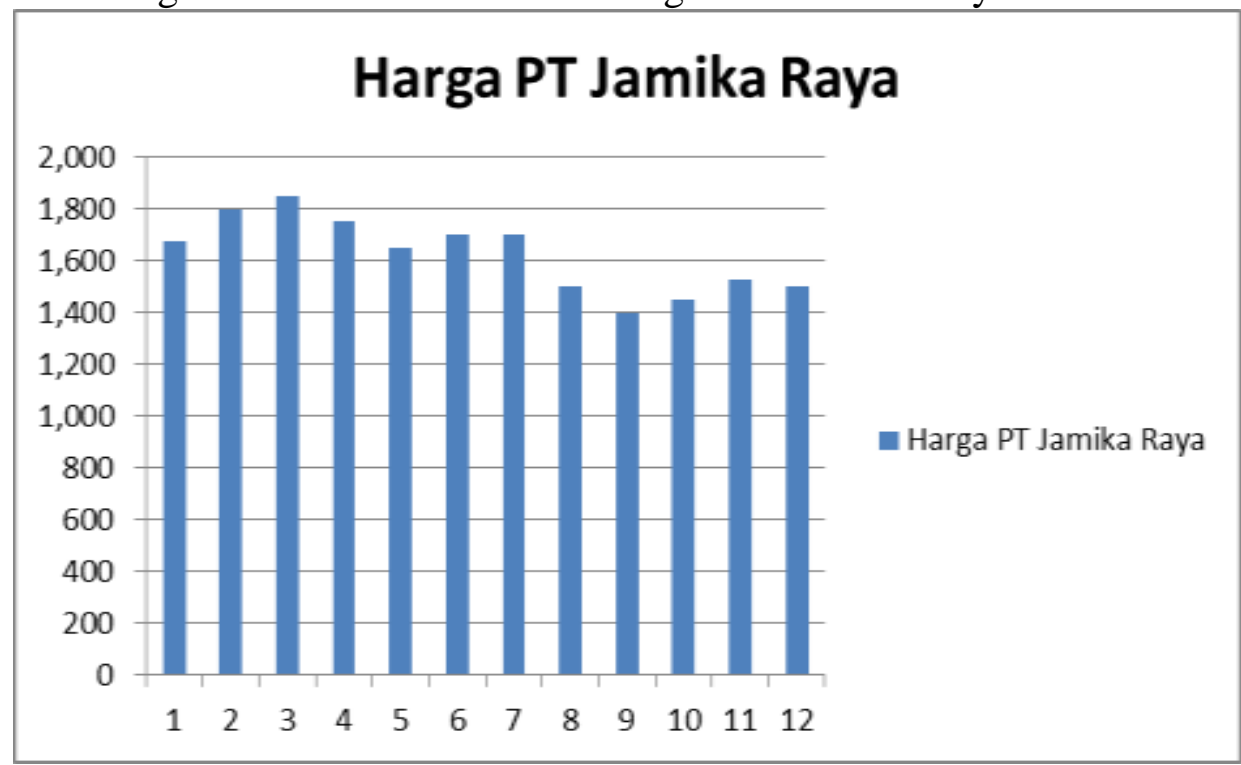

Sumber : PT. Jamika Raya, 2015 
Grafik 2 menunjukan bahwa harga TBS di PT. Jamika Raya selalu berfluktuasi. Harga tertinggi pada bulan maret dengan harga sebesar 1.850 dan harga paling rendah yaitu pada bulan September dengan harga Rp. 1.400 . harga yang berfluktuasi ini meyebabkan harga yang di terima oleh koperasi unut desa (KUD) yang menjual tandan buah segar ke PT Jamika Raya berfluktuasi juga setiap bulannya.KUD yang menjual tandan buah segar ke PT Jamika Raya terdapat di dua kecamatan yaitu Kecamatan Limbur Lubuk Mengkuang dan Bathin II Pelayang. Berdasarkan latar belakang diatas maka penulis tertarik melihat tentang perbnatingan produksi dan harga sawit di Kecamatan Bathin II Pelayang dan Kecamatan Limbur Lubuk Mengkuang judul "Analisis Komparatif Harga Sawit di Koperasi Unit Desa (KUD) di Kecamatan Bathin II Pelayang dan Kecamatan Limbur Lubuk Mengkuang Kabupaten Bungo".

Tujuan Penelitian

Tujuan penelitian ini adalah untuk mengetahui Perkembangan harga harga tandan buah segar (TBS) Koperasi Unit Desa di Kecamatan Bathin II Pelayang dan Limbur Lubuk Mengkuang Kabupaten Bungo dan komparatif harga tandan buah segar (TBS) Koperasi Unit Desa di kecamatan bathin II Pelayang dan Limbur Lubuk Mengkuang di Kabupaten Bungo

\section{METODE PENELITIAN}

Penelitian ini akan dilaksanakanKecamatan Bathin II Pelayang dan Kecamatan Limbur Lubuk Mengkuang, yang memiliki koperasi unit desa (KUD) yang menjual tandan buah segar sawit ke PT jamika Raya. Penelitian ini dilaksanakn dari tanggal 10 Januari 2017 sampai 10 Februari 2017.Jenis data yang digunakan dalam penelitian ini adalah data sekunder, yaitu data yang diperoleh dalam bentuk sudah jadi, dikumpulkan dan diolah oleh pihak perusahaan dan Instansi terkait antara lain Koperasi Unit Desa (KUD) di kecamatan Bathin II Pelayang dan Kecamatan Limbur Lubuk Mengkuang .PT. Jamika Raya, BPS dalam rentang waktu bulan Januari tahun 2010 sampai Desember 2015. Data sekunder dalam penelitian ini adalah Produktivitas TBS dan harga TBS (Tandan Buah Segar) yang datanya diperoleh dari koperasi unit desa (KUD) di Kecamatan Bathin II pelayang dan kecamatan Limbur Lubuk Mengkuang.Dalam penelitian ini menggunakan data Time Series dengan data observasi selama lima tahun dari bulan Januari tahun 2011 sampai dengan Desember tahun 2015.

Metode yang di gunakan untuk menganalisa komparatif produktifitas tandan buah segar (TBS) Koperasi Unit Desa di kecamatan bathin II Pelayang dan Limbur Lubuk Mengkuang di Kabupaten Bungo komparatif harga tandan buah segar (TBS) Koperasi Unit Desa di kecamatan bathin II Pelayang dan Limbur Lubuk Mengkuang di Kabupaten Bungo menggunakan anlisis deskriftif dan di lanjutkan dengan uji-t, menurut (Sugiono, 2012) rumus sebagai berikut

$$
\begin{gathered}
T-T E S T=\frac{\overline{X_{1}}-\overline{X_{2}}}{\sqrt{\frac{S D_{1} 2}{N_{2-2}}+\frac{S D_{2} 2}{N_{2-1}}} \text { dengan }} \\
S D_{1} 2=\left[\frac{\sum X_{1}}{N_{1}}-\left(X_{1}\right)^{2}\right]
\end{gathered}
$$

Dimana:

Keterangan:

$\overline{X_{1}}=$ Rata-rata pada distribusi sampel 1

$\overline{X_{2}}=$ Rata-rata pada distribusi sampel 2

$S D_{1}^{2}=$ Nilai varian pada distribusi sampel 1

$S D_{2}{ }^{2}=$ Nilai varian pada distribusi sampel 2

$N_{1}=$ Jumlah individu pada sampel 1 
$N_{2}=$ Jumlah individu pada sampel 2

Hipotesis:

1. Ho : tidak terdapat komparatif antara ratarata harga tandan buah segar KUD di Kecamatan Limbur Lubuk mengkuang dan KUD di bathin II Pelayang

2. Ha : terdapat komparatif antara rata-rata harga tandan buah segar KUD di Kecamatan Limbur Lubuk mengkuang dan KUD di bathin II Pelayang

Dasar pengambilan keputusan :

1. Jika nilai signifikan atau sig. (2-tailed) $>$ 0,05 maka Ho di terima dan Ha di tolak

2. Jika nilai signifikan atau sig. (2-tailed) $<$ 0,05 maka Ho di tolak dan Ha di terima

\section{PEMBAHASAN}

\section{Lokasi Koperasi Unit Desa yang menjual tandan buah segar ke PT Jamika Raya}

Koperasi yang menjual tandan buah segar (TBS) di PT Jamika Raya Terdapat 6 KUD yang terletak di dau kecamatan yaitu Kecamatan Limbur Lubuk Mengkuang dan Kecamatan Bathin II Pelayang. KUD yang terdapat di Kecamatan Limbur Lubuk Mengkuang dan Kecamatan Bathin II Pelayang adalah sebagai berikut :

1. Kecamatan Limbur Lubuk Mengkuang
a. Desa Tebo Jaya
b. Desa Tuo Limbur
c. Desa Limbur Baru
d. Desa Sekar Mengkuang

2. Kecamata Bathin II Pelayang

a. Desa Pulau kerakap

b. Desa Seberang Jaya

Koperasi Unit Desa (KUD) yang menjual tandan buah segar (TBS) ke PT Jamika Raya memiliki jarak yang berbedabeda hal ini erat hubungannya dengan harga yang di terima oleh petani. Jarak yang di tempuh dari KUD ke PT Jamika raya ini dapat di loihat pada table 2 di bawah ini :

Tabel 2. Jarak KUD yang menjual TBS ke PT Jamika Raya

\begin{tabular}{lc}
\hline Koperasi Unit Desa & Jarak Ke PT Jamika Raya $(\mathrm{Km})$ \\
\hline Pulau Kerakap & 10 \\
Tebo Jaya & 20 \\
Tuo Limbur & 23 \\
Limbur Baru & 26 \\
Sekar Mengkuang & 17 \\
Seberang Jaya & 12 \\
\hline
\end{tabular}

Tabel 2.Menunjukkan jarak koperasi unit desa yang menjual tandan buah segarnya ke PT Jamika Raya, jarak yang terjauh yaitu dari KUD Limbur Baru sejauh $26 \mathrm{Km}$ dan terdekat KUD pulau kerakap. Hal ini erat hubungannya dengan harga yang di berikan oleh KUD ke petani yang menjual tandan buah segarnya ke PT Jamika Raya. Semakin Jauh Jarak KUD ke PT Jamika Raya Maka harga tandan buah segar yang di berikan oleh
KUD semakin rendah , karena biaya transfortasi dan resiko dalam perjalanan. Perjalanan di Limbur Lubuk Mengkuang terkenal dengan relief jalan yang parah, berbukit dan jalannya rusak, hal ini salah satu yang menyebabkan haraga yang di terima oleh petani berfluktuasi

\section{Perkembangan harga tandan buah segar di PT Jamika Raya tahun 2010-2015}


Harga tandan buah segar di PT Jamika Raya selalu mengalami fluktuasi dari tahun ke tahun. Perkembangan harga tandan buah segar PT Jamika Raya dari tahun 2010-2015 fluktuasi yang mengalami peningkatan dan penurunan yang signifikan. Perkembangan harga tandan buah segar selengkapnya dapat di lihat pada gambar 2, di bawah ini :

Gambar. 2. Perkembangan harga tandan buah segar di PT Jamika Raya tahun 2010-2015

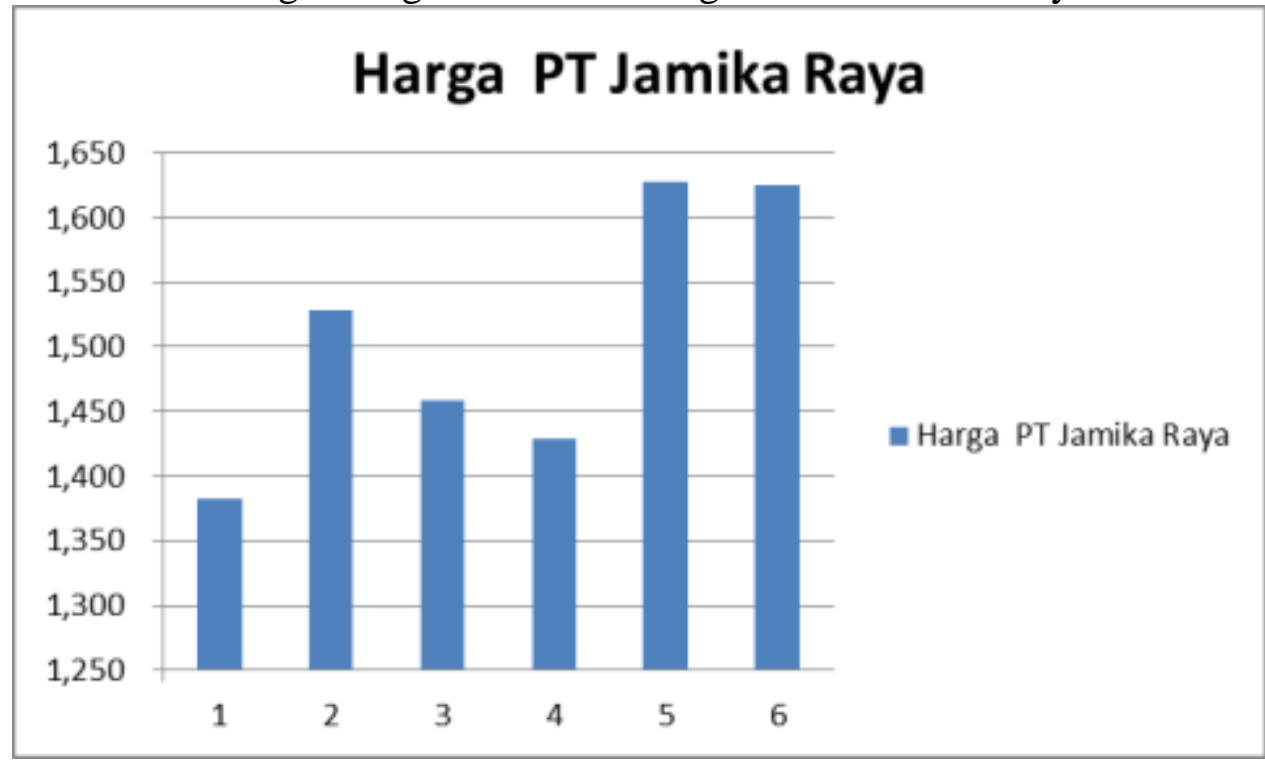

Gambar 2 Harga tandan buah segar tertinggi pada tahun 2014 y aitu sebesar Rp. 1.627 dan terendah pada tahun 2010 yaitu sebesar Rp. 1.382. Harga yang berfluktuasi ini juga beimbas dengan harga yang di terima oleh Koperasi unit desa. Harga tahun 2014 mengalami peningkatan secara drastis dar Rp.1.428 menjadi Rp1.627, hal ini terjadi karena adanya kenaikkan Crude palm oil yang berdampak pada harga tandan buah segar.

Perkembangan harga tandan buah segar di KUD Kecamatan Limbur Lubuk
Mengkuang dan KUD Bathin II Pelayang tahun 2010-2015

Koperasi unit desa (KUD) yang berada di Kecamatan Limbur Lubuk mengkuang dan Bathin II Pelayang menjual hasil tandan buah segar (TBS) ke PT Jamika Raya. Harga yang Lubuk mengkuang dan Bathin II Pelayang tidak sama atau berbeda setiap tahun, selalu mengalami fluktuasi, selengkapnya dapat di lihat di gambar 3 di bawah ini di terima oleh KUD yang berada Limbur

\section{Gambar 3. Perkembangan harga tandan buah segar di KUD Kecamatan Limbur Lubuk Mengkuang dan KUD Bathin II Pelayang tahun 2010-2015}




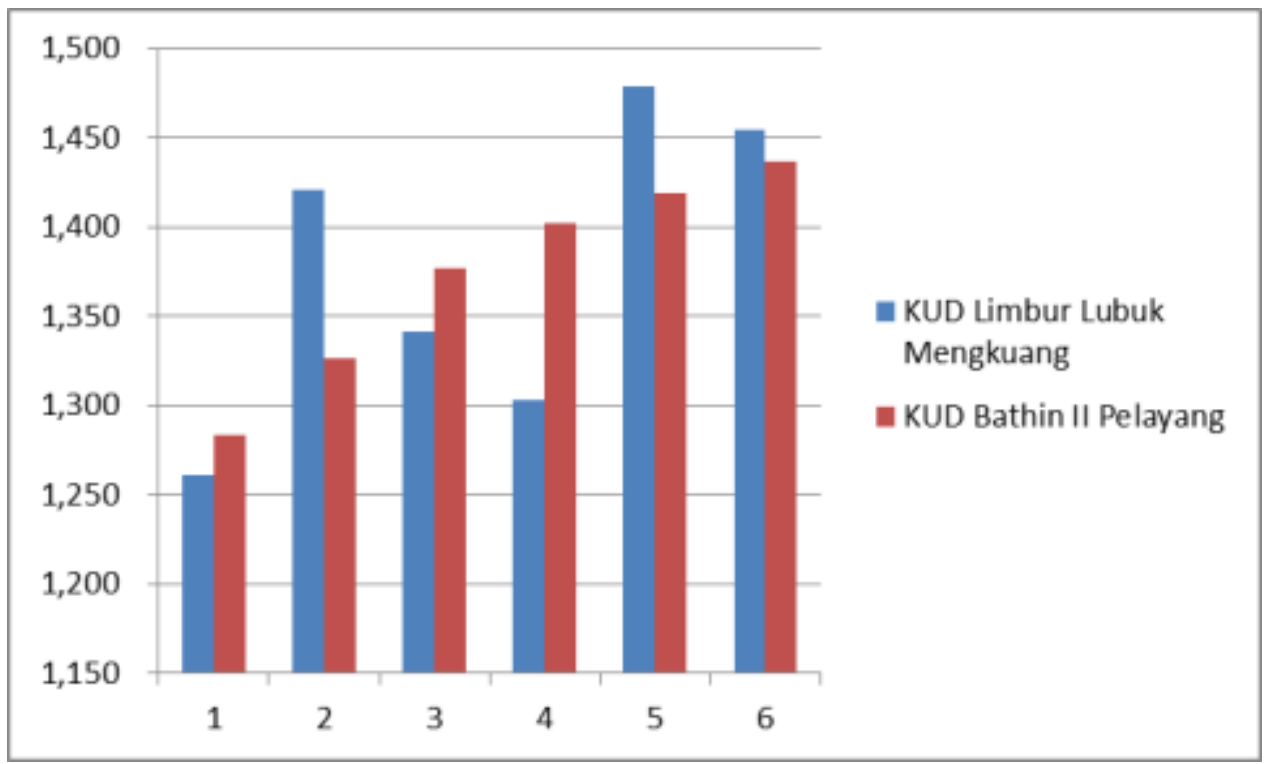

Gambar 3. Menunjukkan bahwa di koperasi unit desa yang berada di Kecamatan Limbur

Lubuk Mengkuang dan Kecamatan Bathin II Pelayang selalu berfluktuasi. Harga tertinggi pada tahun 2014 ,KUD di Limbur Lubuk Mengkuang yaitu sebesar Rp1.479 dan terendah tahun 2010 , KUD di Limbur Lubuk Mengkuang. Hal ini menunjukkan harga tertinggi dan terendah terdapat di KUD Kecamatan Limbur Lubuk Mengkuang namun untuk kecamatan bathin II Pelayang juga ada data tertinggi pertahun yaitu pada tahun 2012 dan tahun 2013. Perubahan harga yang terjadi di dua kecamatan yaitu Kecamatan Limbur Lubuk Mengkuang dan Kecamatan Bathin II Pelayang terjadi karena jarak antar KUD yang berbeda serta relief jalan yang dilalui semuanya berhubungan dengan biaya pengangkutan dan resiko yang di hadapi oleh koperasi unit desa (KUD)

\section{Analisis Komparatif tandan buah segar di Kecamatan Limbur Lubuk Mengkuang dan Kecamatan Bathin II Pelayang}

Koperasi unit desa di Kecamatan Limbur Lubuk Mengkuang dan Bathin 2 Pelayang memiliki harga yang berbeda. Perkembangan harga tandan buah segar KUD di Kecamatan Limbur Lubuk Mengkuang dan Kecamatan Bathin II Pelayang tahun 2010 sampai 2015 di analisa dengan uji Independen Sample T-Tes untuk melihat perbedaan harga KUD di Kecamatan Limbur Lubuk Mengkuang dan Kecamatan Bathin II Pelayang, untuk selengkapnya dapat di lihat pada tabel 2 di bawah ini: 
Tabel 2. Hasil Analisis Komparatif Tandan Buah Segar KUD di Kecamatan Limbur Lubuk Mengkuang dan Kecamatan Bathin II Pelayang

\begin{tabular}{|c|c|c|c|c|c|c|}
\hline \multicolumn{7}{|c|}{ Independent Samples Test } \\
\hline & & \multicolumn{2}{|c|}{$\begin{array}{c}\text { Levene's Test for } \\
\text { Equality of } \\
\text { Variances } \\
\end{array}$} & \multicolumn{3}{|c|}{ t-test for Equality of Means } \\
\hline & & $\mathrm{F}$ & Sig. & $\mathrm{t}$ & df & $\begin{array}{l}\text { Sig. (2- } \\
\text { tailed) }\end{array}$ \\
\hline $\begin{array}{l}\text { Harga } \\
\text { TBS }\end{array}$ & $\begin{array}{l}\text { Equal } \\
\text { varian } \\
\text { ces } \\
\text { assum } \\
\text { es } \\
\text { Equal } \\
\text { varian } \\
\text { ces } \\
\text { not } \\
\text { assum } \\
\text { es }\end{array}$ & 2.017 & . 158 & $\begin{array}{l}-.980 \\
\\
-.980\end{array}$ & 142 & .329 \\
\hline
\end{tabular}

Tabel 2. Menunjukkan bahwa Hasil Analisis Komparatif tandan buah segar KUD di Kecamatan Limbur Lubuk Mengkuang dan Kecamatan Bathin II Pelayang dengan menggunakan Independent Sample T-Test menunjukkan nilai Sig.(2tailed) sebesar 0,329>0,05, maka sesuai dengan hasil pengambilan keputusan Independent Sample T-Test maka dapat di simpulkan bahwa Ho di terima dan $\mathrm{Ha}$ di tolak, artinya tidak terdapat Komparatif anta rata-rata KUD di Kecamatan Limbur Lubuk Mengkuang dan Kecamatan Bathin II Pelayang. Kedua KUD ini tidak terikat satu sama lain.

\section{KESIMPULAN DAN SARAN}

Kesimpulan

1. Perkembangan harga harga tandan buah segar (TBS) Koperasi Unit di Desa Limbur Lubuk Mengkuang Kabupaten Bungo dan Kecamatan Bathin II Pelayang

2. Tidak ada komparatif harga tandan buah segar (TBS) Koperasi Unit Desa di Limbur Lubuk Mengkuang di Kabupaten Bungo dan Kecamatan Bathin II Pelayang
Saran

1. Pemerintah harus lebih memperhatikan harga tadan buah segar (TBS), agar pendapatan yang di peroleh oleh petani bisa tinggi dan bisa meningkatkan perekonomian petani

2. Perlunya perhatian pemerintah terhadapa infrastruktur jalan di desa terutama untuk mengangkut hasil produksi pertanian

\section{DAFTAR PUSTAKA}

Badan Pusat Statistik Provinsi Jambi, 2014. Produksi tahunan dan luas area perkebunan kelapa sawit jambi tahun 2009-2013. Diakses tanggal 17 April 2014 dari jambi.bps.go.id

Dinas Perkebunan Provinsi Jambi . 2006. Statistika Perkebunan tahun 2005 (angka tetap) Jambi

PT. Jamika Raya. 2016. Harga Tandan Buah segar di PT Jamika Raya tahun 2010-2015. Bungo 
KUD Limbur Baru . 2016. Harga Tandan Buah Segar KUD Limbur Baru tahun 2010-2015.Bungo

KUD Seberang Jaya. 2016. Harga Tandan Buah Segar KUD Seberang Jaya tahun 2010-2015.Bungo

KUD Sekar Mengkuang . 2010. Harga Tandan Buah Segar KUD Sekar Mengkuang tahun 2010-2015. Bungo

KUD Pulau Kerakap 2016. Harga Tandan Buah Segar KUD Pulau Kerakap tahun 2010-2015.Bungo

KUD Tebo Jaya . 2016. Harga Tandan Buah Segar KUD Tebo Jaya tahun 2010-2015.Bungo

KUD Tuo Limbur .2016. Harga Tandan Buah segar KUD Tuo Limbur tahun 2010-2015.Bungo

Sugiyono. 2012. Metode penelitian Kualitatif Kuantititatifdan R\& D. Bandung. Alfabeta

Toar. O, Karamoy.H \&Wokas .H (2017) analisis perbandingan harga jual Produk dengan menggunakan metode cost plus pricing dan mark up pricing pada dolpin donuts Bakery . Jurnal EMBA 1 (2) .2040-2050

Widayana. E. 2016. Pendekatan Pengendalian Fluktuasi Harga Tandan Buah Segar terhadap Pendapatan Petani Kelapa Sawit. Habitat 27 (3).103-108

Wulandari. S.A \& Kemala .N (2016) .Kajian komoditas Unggulan Sub Sektor perkebunan di Provinsi Jambi. Jurnal Ilmiah Universitas Batang Hari 16 (1). 